\title{
What Drives Consumers in Poland and the Czech Republic When Choosing Engine Oil Brand?
}

\author{
Artur Wolak, Kamil Fijorek, Grzegorz Zając, Vojtěch Kumbár
}

\begin{abstract}
A B S T R A C T
Objective: The objective of the research was to study consumer decision-making and purchasing preferences when buying engine oils to reveal the presence of consumer preference heterogeneity.

Research Design \& Methods: Survey data were collected from Polish and Czech consumers by using a self-administered questionnaire. The main data analysis tools used in the study were the finite mixture models and semantic differential.

Findings: Consumers do not constitute a single homogenous group. They cluster into four segments with differing importance profiles. The study found that the largest consumer segment, over one-third of consumers, consider the quality classification, viscosity classification, and OEM specification as the most important criteria during the decision-making process.

Implications \& Recommendations: As the largest extracted consumer segment includes drivers who are mainly guided by technical specification in the purchasing process, we recommend producers to put additional efforts to provide clearly visible technical specifications on the product label.
\end{abstract}

Contribution \& Value Added: The study fills an important gap regarding the lack of empirical research in the context of buying engine oils. The undertaken research indicates that the attention of future consumer research into brand attachment should be shifted from brand loyalty studies towards the study of brand familiarity. The paper presents very valuable model-based consumer segmentation.

\begin{tabular}{ll}
\hline Article type: & research article \\
Keywords: & $\begin{array}{l}\text { engine oil; consumer behaviour; choice heterogeneity; consumer seg- } \\
\text { mentation; model-based clustering }\end{array}$ \\
JEL codes: & D12, M31
\end{tabular}
Received: 25 September 2019 Revised: 24 November $2019 \quad$ Accepted: 1 December 2019

\section{Suggested citation:}

Wolak, A., Fijorek, K., Zając, G., \& Kumbár, V. (2019). What Drives Consumers in Poland and the Czech Republic When Choosing Engine Oil Brand?. Entrepreneurial Business and Economics Review, 7(4), 165-184. https://doi.org/10.15678/EBER.2019.070410 


\section{INTRODUCTION}

In recent years, scholarship devoted considerable effort to understanding the processes behind customers' purchase decisions. A large portion of this research focused on two basic aspects: information acquisition and information integration. Pre-purchase information search is a critical step in the buying process of consumers, especially in the case of highly involving products and services. Over the years, marketing researchers allocated much work to investigating consumer information-seeking behaviour (Mourali, Laroche, \& Pons, 2005). Knowing what the consumer preferences are is the Holy Grail for almost all manufacturers and retailers that are subjected to the market competition. Each product and each market have their own challenges in that regard. There is a much different decision process when a consumer considers buying inexpensive and frequently purchased products than when the opposite is the case. The complexity is still multiplied by the other dimensions, e.g. whether the consumer is equipped with enough knowledge to make an informed decision, whether there are any time constrains, or whether the decision will have any longlasting impact on the consumer's well-being. As a result, research outcomes obtained for a particular product and market may not be directly transferable to the different product on the same market or even the same product but on a different market. This is a highly undesirable observation, as it causes the need for considerable expenditures towards marketing research. The same holds true even for infrequently purchased products, as in the case of our research: consumer car engine oils. The producers of engine oils, as any other producers, need to know what the main drivers of consumer choices are in order to successfully compete and increase their market share and profitability. Moreover, consumers are rarely a homogenous group with strongly focused preferences. More frequently consumers are heterogeneous with regard to their preferences, with a number of segments and their sizes typically unknown a priori. Unfortunately, the petrochemical literature is rather scarce in this regard. That is the main reason why we selected this particular research topic and conducted a study on 200 respondents from Poland and the Czech Republic.

Before moving to the literature review, a necessary context regarding the current shape of oil markets in Poland and the Czech Republic needs to be provided. Poland is the eleventh state in Europe in terms of area (over 310 thousand $\mathrm{km}^{2}$ ). As of the beginning of 2018, the population of Poland amounts to nearly 38.5 million people. According to the Central Register of Vehicles (CRV), as of June 2017, the number of vehicles registered in Poland amounts to nearly 29 million $(\mathrm{m})$; including over $22 \mathrm{~m}$ cars and over 3.2 $\mathrm{m}$ lorries; the remaining part includes buses, motorcycles, and mopeds (http://cepik.gov.pl). The Czech Republic is the twenty-first in Europe in terms of area (80 thousand $\mathrm{km}^{2}$ ). As of January 2019, the population of the Czech Republic amounts to nearly 11 million people. According to the Czech CRV, as of June 2019, the number of vehicles registered in the Czech Republic amounts to over $8 \mathrm{~m}$; including nearly $6 \mathrm{~m}$ passenger cars, over $0.5 \mathrm{~m}$ lorries, nearly 22 thousand buses; the remaining part includes trucks, motorcycles, mopeds, and tractors (SDA: Car Importers Association).

According to the report of the POPiHN (Polish Organisation of Oil Industry and Trade), the lubricants market in Poland is stable in terms of its sales volume. Since the end of 2010, annual fluctuations of the market remain within the range of no more than $5 \%$ with its average size of 225 thousand tonnes in the said period. Of this amount, $55-60 \%$ are automotive 
oils. A similar situation is observed on the Czech market; yet, with an upward trend in recent years. According to the report of the Czech Statistical Office, in 2018 the lubricants and lubricant oils consumption was 216 thousand tonnes, which is more than in previous years: 202 thousand tonnes in 2017 and 195 thousand tonnes in 2016 (Cesky Statisticky Urad).

When looking at the long-term perspective of the oil market, an increase in the share of motor oils for passenger cars is noteworthy, as it comprises about $46.5 \%$ of all lubricating oils sold, and within the automotive oils segment they constitute about $80 \%$; in 2018 it was almost 110 thousand tonnes. The dominant group of lubricant oils used in the automotive industry in the segment of passenger cars and light commercial vehicles - are $0 \mathrm{~W}-\mathrm{X}$ and $5 \mathrm{~W}-\mathrm{X}$ oils. Noteworthy, there appeared a marked increase in sales of synthetic oils for passenger cars and in terms of the whole lubricants market, this share grew from $5.5 \%$ in 2007 to $18.3 \%$ in 2018. Consequently, the sales of this group of products remains the largest on the market, ahead of industrial hydraulic oils, and - due to this fact - the present research focuses on drivers who use fully synthetic engine oils (POPiHN, 2018). At the same time (2007-2018), mineral oils for passenger cars and trucks saw the largest decline in sales. This is related to the ongoing process of modernisation of vehicle fleets in Poland and the Czech Republic. Similar trends are also observed in more advanced markets, e.g. French or German.

This paper is divided into several sections. Firstly, a thorough literature review is presented. Then, we outline the survey design and - as the main aim of the study was to investigate the possible presence of consumer preference heterogeneity - provide an appropriate statistical methodology. The main part of the paper focuses on the research results. Finally, practical recommendations for marketers who operate in the oil markets are given, the limitations of the research are critically assessed and the outlook for the future research in this area is provided.

\section{LITERATURE REVIEW}

Prior to conducting the research, we prepared a careful review of existing international and domestic scientific literature. Several studies from the Asian and African oil markets were found. Zakir (2011) studies the oil market in Pakistan. The author explores consumer attitude towards buying a PSO lubricant (Pakistan State Oil) and is mainly interested in finding out the reasons behind PSO's low market share, but he also identifies and investigates the key areas that drive consumers towards purchasing a lubricant: viscosity/thickness, prior experience, improved durability, and mileage. A sample of 120 subjects was analysed through a questionnaire which revolved around a few basic attributes of consumer purchase decision. Zakir (2011) states that advertisement and promotional campaigns play a role as a short-term strategy, increasing sales for just a limited period of time.

Alavijeh, Fattahi, and Moshfegh (2019) study the oil market in Iran. In total, they use 74 questionnaires (industrial lubricants buyer organisations) for data analysis. The authors compare the effects of price and brand on the industrial customers' buying choices and their results indicate that there appear significant effects of both. The effects of customer complementary information - with no precise specification - were not significant. Let us indicate that the authors analyse industrial buyers and as such their results may not be fully applicable for individual customer markets. Thereby, their results have limited usefulness in the context of this research. 
Another study was conducted by researchers who analysed the Nigerian oil market. A research questionnaire was administered to 1890 vehicle owners, randomly selected from the national register maintained by Lagos State Motor Vehicle Administration Agency in 2003-2013. The correlation and regression analysis were used to test the hypothesis that there is no significant relationship between brand recognition and customer impulse buying behaviour. The authors reveal that there is a significant relationship between the examined factors (Olanipekun, Rasheed, \& Sydney, 2015). The study recommends that marketers of lubricants should develop innovative packaging strategies that will appeal to and attract consumers in an exceptional way to trigger impulse buying.

Researchers in India were interested in finding attributes of oil brand positioning (Srivastava, 2016). They applied multiple regression analysis to find out the relationship between independent variables - price, quality, availability, customer satisfaction - and the dependent variable of purchase decision. A positive correlation between the purchasing decision and price, consumer satisfaction and a negative correlation between the purchasing decision and quality/availability were found. The authors also construct an interesting two-dimensional (price and quality) perceptual map for the major brands of lubricant oils available in India.

Pawar and Khandelwal (2011) analysed the dynamics within competitive automotive lubricants markets with large powers of the intermediaries on the supply side. The authors underline that the analysis of consumer buying behaviour shows that there is a need to spread the awareness amongst the consumers regarding product differentiation.

Srivastava (2018) conducted an empirical study in Delhi region to find the perception of consumers towards the automotive lubricants. In her research four factors have been identified. The first factor is product trustworthiness, which combines credibility, reputation, innovativeness, and commitment. The second factor is product quality, which links superiority and reliability. The third factor is marketing strategy, which mixes advertising, packaging, and promotion. The fourth factor is accessibility, which blends price, availability, and purchasing location.

Unfortunately, it was impossible to retrieve from scientific databases any previous studies concerned with investigating consumer decision-making and purchasing preferences in the specific context of engine oils purchases in European markets, especially Poland and the Czech Republic. One possible reason for this scarcity of articles may be that such research is conducted mainly or even solely by the private companies, which have little incentive to make their research public. The goal of this paper is to at least partially fill the existing knowledge gap.

\section{MATERIAL AND METHODS}

\section{Survey Design}

The statistical research covered a group of 100 drivers from Poland and 100 drivers from the Czech Republic. We assumed that 200 drivers would be a study sample large enough to obtain reliable analysis results that would give grounds to draw substantive conclusions. The empirical part of the research was conducted by means of a survey. Questionnaires were delivered to respondents electronically. The respondents were invited to participate in this study through snowball sampling (chain-referral sampling). This is a non-probability 
sampling technique, in which a pool of initial respondents nominated other participants through virtual and non-virtual social networks - who met the eligibility criteria and could potentially contribute to the study. This sampling technique is often used in hidden populations, which are difficult to access for researchers due to the fact that there are no lists or other obvious sources for locating the members of the population.

The full questionnaire consisted of 21 questions, including 15 closed questions and 6 open questions. The design of the questionnaire was preceded by an in-depth analysis of the available literature in order to create such survey questions that would correctly reflect the multi-faceted construction of the studied phenomenon. A detailed discussion of this aspect of the study is provided in Appendix A. Out of 21 survey questions, the one whose answers became the subject of the closest analysis was formulated as follows: "Please indicate the significance of the criteria determining the choice of the engine oil brand." The respondents evaluated individual criteria on a five-point scale (unimportant, not very important, quite important, important, very important) with a possibility to select an option "no opinion." The respondents assessed the subjectively perceived importance of 13 different criteria: oil price, brand loyalty, OEM specification (e.g. VW, MB, GM), the scope of information provided on the oil label, qualitative classification (e.g. API, ACEA), viscosity grade (SAE J300, e.g. 5W-30), brand familiarity, radio and TV ads, recommendations of the supplier, recommendations of the car manufacturer, recommendations of the authorised service station, recommendations of the local garage/car service, and recommendations provided by the family and friends.

\section{Research Objective}

The objective is twofold: (1) to identify/examine factors behind consumer choices when buying engine oils and (2) to examine the degree of heterogeneity between purchasers of engine oils.

\section{Research Hypotheses}

Before conducting data analysis, we formulated the following scientific hypotheses. Hypothesis $A(H A)$ : "Consumers from Poland and the Czech Republic have noticeably different decision-making processes when faced with engine oil purchase." This hypothesis will be investigated by comparing importance profiles among groups of survey respondents from both countries. We should indicate that there is no strong prior evidence to support this hypothesis. As a result, the acceptance or rejection of this hypothesis is equally probable. Hypothesis B (HB): “Consumers do not constitute a single homogenous group. They cluster into a priori unknown number of segments with differing importance profiles." This hypothesis will be investigated using a model-based clustering algorithm. This method will be applied to the respondents from both countries separately, if the HA is not rejected, and also the number of segments will be allowed to differ between countries. In the case when the HA does not hold conclusively, the model-based clustering will be applied to both groups merged together.

\section{Data Analysis Methods}

The main tool used in the research is the finite mixture model. Finite mixture models have been used for more than 100 years but have seen a significant boost in popularity over the last decades mainly due to the tremendous increase in the available computing 
power. The areas of application of mixture models range from biology and medicine to physics, economics, and marketing. These models can be applied to data, in which observations originate from various groups and group memberships are unknown (Peel \& McLachlan, 2000). An important area of application of mixture models is market segmentation, in which finite mixture models replace more traditional cluster analysis (Leisch, 2004). This is precisely the case considered in this paper.

Finite mixture models with a fixed number of components are usually estimated with the expectation-maximization (EM) algorithm within a maximum likelihood framework or with MCMC sampling within a Bayesian framework (Wedel \& Kamakura, 2001). For the purposes of this research, the EM method has been applied and thus the mathematical model for latent classes has been introduced and parameter estimation briefly discussed. The finite mixture models with $\mathrm{K}$ components are of the following formula:

$$
h(y \mid x, \psi)=\sum_{k=1}^{K} \pi_{k} f\left(y \mid x, \theta_{k}\right), \pi_{k} \geq 0, \sum_{k=1}^{K} \pi_{k}=1
$$

in which $y$ is an univariate or multivariate dependent variable with conditional density $h$, $\mathrm{x}$ is an optional vector of independent variables, $\pi_{\mathrm{k}}$ is the prior probability of component $k, \theta_{k}$ is the component specific parameter vector for the density function $f$, and $\psi=\left(\pi_{1}, \ldots\right.$ $\left., \pi_{\kappa}, \theta^{\prime}{ }_{1}, \ldots, \theta^{\prime}\right)^{\prime}$ is the vector of all parameters. For example, for multivariate normal $f$ and $x \equiv 1$, a mixture of Gaussians, also known as Gaussian model-based clustering is obtained. The posterior probability that observation belongs to class $\mathrm{j}$ is given by:

$$
P(j \mid x, y, \psi)=\frac{\pi_{j} f\left(y \mid x, \theta_{j}\right)}{\sum_{k=1}^{K} \pi_{k} f\left(y \mid x, \theta_{k}\right)}
$$

The posterior probabilities can be used to segment data by assigning each observation to the class with maximum posterior probability. In the above formula $f\left(\cdot \mid \cdot, \theta_{k}\right)$ is referred to as mixture components or classes, while the groups in the data are induced by these components as clusters.

Parameter estimation of finite mixture models is considered next. The mixture is assumed to consist of $\mathrm{K}$ components, in which each component follows a parametric distribution. Each component has a weight assigned, which indicates the a priori probability for an observation to come from this component, while the mixture distribution is given by the weighted sum over the $\mathrm{K}$ components (Leisch, 2008). The log-likelihood of a sample of $\mathrm{N}$ observations $\left\{\left(\mathrm{x}_{1}, \mathrm{y}_{1}\right), \ldots,\left(\mathrm{x}_{\mathrm{N}}, \mathrm{y}_{\mathrm{N}}\right)\right\}$ is given by:

$$
\log L=\sum_{n=1}^{N} \log h\left(y_{n} \mid x_{n}, \psi\right)=\sum_{n=1}^{N} \log \left(\sum_{k=1}^{K} \pi_{k} f\left(y_{n} \mid x_{n}, \theta_{k}\right)\right)
$$

and it usually cannot be maximized directly. The most popular method for maximum likelihood estimation of the parameter vector $\psi$ is the iterative EM algorithm (Dempster, Laird, \& Rubin, 1977). In the E-part, the posterior class probabilities for each observation is estimated: $\hat{p}_{n k}=P\left(k \mid x_{n}, y_{n}, \hat{\psi}\right)$ using Equation (2) and derive the prior class probabilities as $\hat{\pi}_{k}=\frac{1}{N} \sum_{n=1}^{N} \hat{p}_{n k}$ and in the M-part, the log-likelihood for each component is maximised separately using the posterior probabilities as weights:

$$
\max _{\theta_{k}} \sum_{n=1}^{N} \hat{p}_{n k} \log f\left(y_{n} \mid x_{n}, \theta_{k}\right)
$$

The $\mathrm{E}$ and $\mathrm{M}$-steps are repeated until the likelihood improvement falls under a small prespecified threshold. During the described process, as the EM algorithm converges only to the local maximum of the likelihood, it should be run repeatedly using different starting values (Leisch, 2004). In real applications, the number of components is unknown and has to be 
estimated. This can be achieved by fitting models with an increasing number of components and then comparing them using the widely known BIC (Bayesian Information Criterion).

\section{RESULTS AND DISCUSSION}

\section{Characteristics of the Sample}

The survey was addressed to both women and men; however, a vast majority of women gave a negative answer ("no") to the control question "Do you make decisions or participate in the decision-making process when it comes to changing the engine oil?" Hence, we decided that the analysis would be conducted solely on men, so the sample size of 200 represents only men.

The basic characteristics of the sample are presented in Table 1. As is typical for the vast majority of survey research presented in the literature, the survey sample was mildly skewed towards younger persons. ${ }^{1}$ As many as $90 \%$ of respondents were in the age between 18 and 50 years old, with the range of 31-40 years (37\%) dominating in Poland and the range of 21-30 (33\%) dominating in the Czech Republic. As visible in Table 1, the age of the respondents is not particularly concentrated within a narrow range; however, the data analysis results may not fully represent older drivers (60 y.o. and above). The majority of the respondents (72\% in Poland, $52 \%$ in the Czech Republic) held a Bachelor's or Master's degree. As many as $55 \%$ of Polish respondents live in a city of over 250,000 inhabitants, whereas in the group from the Czech Republic such respondents constituted $36 \%$ while the most numerous was the group consisting of inhabitants of rural areas (43\%).

Table 1. The basic characteristics of the sample $(n=200)$

\begin{tabular}{|l|c|c|c|c|c|}
\hline \multicolumn{1}{|c|}{ Place of residence } & Poland & $\begin{array}{c}\text { Czech } \\
\text { Republic }\end{array}$ & Age & Poland & $\begin{array}{c}\text { Czech } \\
\text { Republic }\end{array}$ \\
\hline Rural area & $23 \%$ & $43 \%$ & 20 and below & $3 \%$ & $18 \%$ \\
\hline City up to 50,000 residents & $11 \%$ & $10 \%$ & $21-30$ & $32 \%$ & $33 \%$ \\
\hline City up to 100,000 residents & $6 \%$ & $7 \%$ & $31-40$ & $37 \%$ & $28 \%$ \\
\hline City up to 250,000 residents & $5 \%$ & $4 \%$ & $41-50$ & $18 \%$ & $12 \%$ \\
\hline City above 250,000 residents & $55 \%$ & $36 \%$ & 51 and over & $10 \%$ & $9 \%$ \\
\hline Education & $1 \%$ & $4 \%$ & $\begin{array}{c}\text { Secondary } \\
\text { education }\end{array}$ & $12 \%$ & $27 \%$ \\
\hline $\begin{array}{l}\text { Basic education /vocational education } \\
\text { and lower secondary education }\end{array}$ & $15 \%$ & $27 \%$ & $\begin{array}{c}\text { Higher } \\
\text { education }\end{array}$ & $72 \%$ & $52 \%$ \\
\hline In college &
\end{tabular}

Source: own study.

Over $50 \%$ of the cars used by respondents had the overall mileage above 150,000 $\mathrm{km}$, with the range of $200,000-249,999 \mathrm{~km}(24 \%)$ being dominant in Poland and with the range of 150,000-199,999 km (19\%) being the most common in the Czech Republic (Table 2). Approximately $30 \%$ of the cars had a mileage below $100,000 \mathrm{~km}$, both in Poland and in the Czech Republic. $47 \%$ of the respondents had cars with a diesel engine, while

\footnotetext{
${ }^{1}$ For further examples of this phenomenon, see another research conducted in the Polish context (Smol, Avdiushchenko, Kulczycka, \& Nowaczek, 2018).
} 
$53 \%$ of the respondents had cars with a gasoline engine. Over $60 \%$ of the cars were manufactured after 2005, with the range of 2000-2004 (33.7\%) being dominant in Poland and with the range of 2005-2009 (31\%) being dominant in the Czech Republic. Approximately $10 \%$ of the respondents used cars that were over 18 years old, i.e. produced before 2000. Over $80 \%$ (Poland) and $90 \%$ (Czech Republic) of the cars were equipped with engine capacity below $2.00 \mathrm{dm} 3$, with the range of $1.51-2.00$ (64\% in Poland and $58 \%$ in the Czech Republic) being the most frequent.

Table 2. Characteristics of the respondents' cars $(n=200)$

\begin{tabular}{|c|c|c|c|c|c|}
\hline Car mileage [km] & Poland & $\begin{array}{c}\text { Czech } \\
\text { Republic }\end{array}$ & Engine & Poland & $\begin{array}{c}\text { Czech } \\
\text { Republic }\end{array}$ \\
\hline$<50,000$ & $13 \%$ & $16 \%$ & Diesel & $47 \%$ & $47 \%$ \\
\hline $50,000-99,999$ & $17 \%$ & $15 \%$ & Gasoline & $53 \%$ & $53 \%$ \\
\hline $100,000-149,999$ & $12 \%$ & $13 \%$ & & & \\
\hline $150,000-199,999$ & $11 \%$ & $19 \%$ & \multicolumn{3}{|c|}{ Year of car production } \\
\hline $200,000-249,999$ & $24 \%$ & $14 \%$ & $<1994$ & $1 \%$ & $0 \%$ \\
\hline $250,000-300,000$ & $15 \%$ & $10 \%$ & 1995-1999 & $8 \%$ & $10 \%$ \\
\hline$>300,000$ & $8 \%$ & $13 \%$ & $2000-2004$ & $31 \%$ & $23 \%$ \\
\hline \multicolumn{3}{|c|}{ Engine capacity } & $2005-2009$ & $25 \%$ & $31 \%$ \\
\hline Below $1.0 \mathrm{dm}^{3}$ & $2 \%$ & $2 \%$ & 2010-2014 & $23 \%$ & $21 \%$ \\
\hline $1.00-1.50 \mathrm{dm}^{3}$ & $16 \%$ & $30 \%$ & $>2015$ & $12 \%$ & $15 \%$ \\
\hline $1.51-2.00 \mathrm{dm}^{3}$ & $64 \%$ & $58 \%$ & & & \\
\hline $2.01-2.50 \mathrm{dm}^{3}$ & $12 \%$ & $5 \%$ & & & \\
\hline $2.51-3.00 \mathrm{dm}^{3}$ & $3 \%$ & $3 \%$ & & & \\
\hline Above $3.00 \mathrm{dm}^{3}$ & $3 \%$ & $2 \%$ & & & \\
\hline
\end{tabular}

Source: own study.

It is clearly visible that the data represent a broad variety of cars. There are various mileages and "years of production" present. Furthermore, the engine type and engine capacity are realistically represented in the data sample. We may conclude that from this technical viewpoint that the data give a strong foundation for further analysis.

\section{The Semantic Differential}

The collected data allows us to elaborate graphical profiles (semantic differentials) of the examined criteria, broken down by the nationality of respondents. The semantic differential (SD) is a multidimensional scale for testing attitudes towards specific objects in this case engine oils - which allow for a quantitative assessment of differences in terms of specific concepts (here: criteria) for the indicated groups ${ }^{2}$. Semantic differentials enable the assessment of the intensity of separate components of tested attitudes. Thus, the semantic differential was used to analyse such responses of surveyed subjects that were related to the significance of 13 criteria determining the choice of oil brand. As mentioned in the "Materials and Methods" section, the questionnaire included a fivepoint scale with the option of a "no opinion" answer. Figure 1 contains the average values of the answers obtained, resulting from converting the scale expressed in words to

\footnotetext{
${ }^{2}$ Chráska and Chrásková (2016) provide more detailed information regarding this method.
} 
a numerical scale with values from 1 to 5 points. Furthermore, we assumed that the answer "no opinion" would be combined with the answer "unimportant" and would also receive the value 1 . In the case of consumer surveys, the lack of any opinion regarding the level of importance of a given criterion may mean a state other than answering "unimportant;" however, in the collected material, the "no opinion" answer constituted a small percentage of the total answers. Therefore, it could be assumed that such approach would not lead to the distortion of the results of the data analysis.

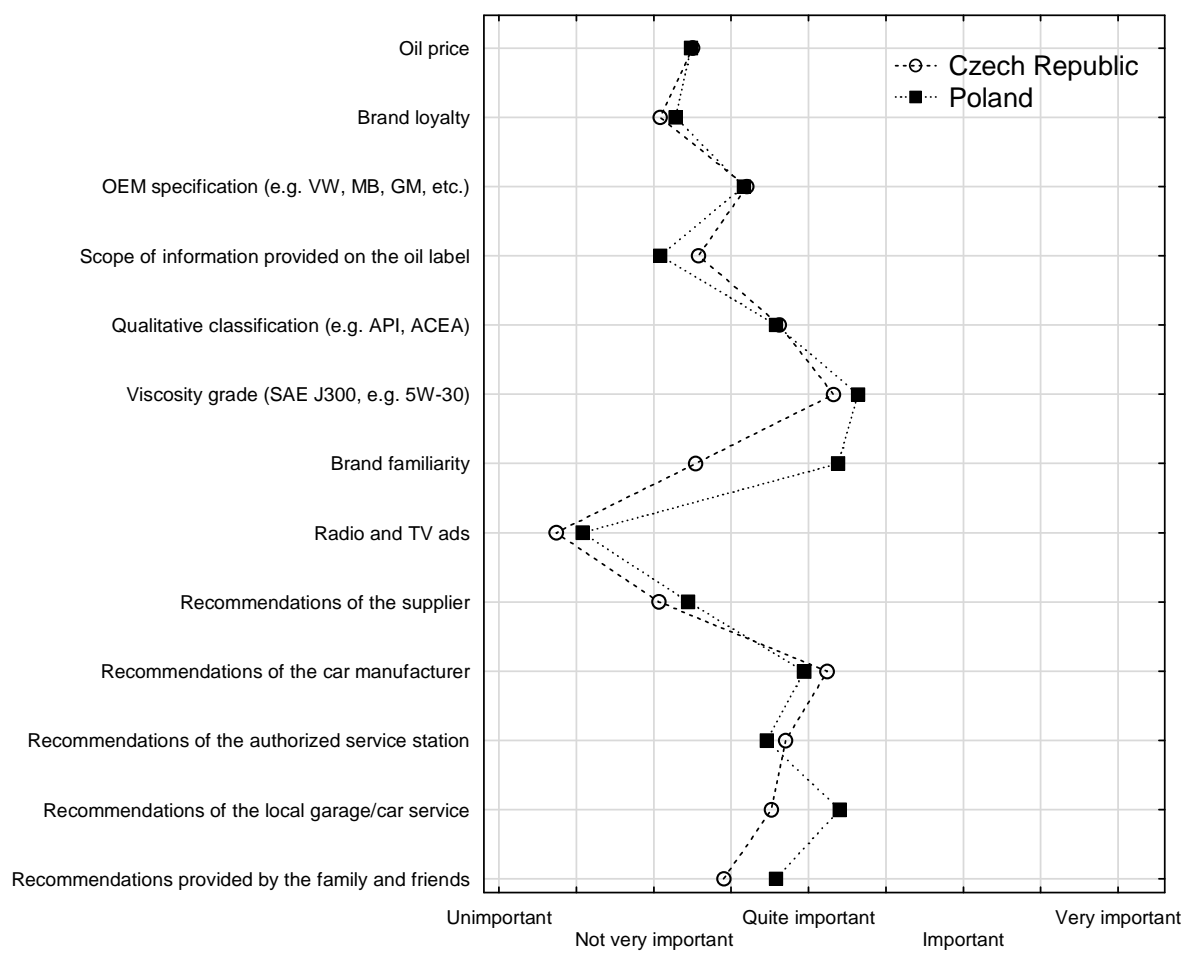

Figure 1. Semantic differential for the importance of the analysed criteria as indicated by respondents from Poland and the Czech Republic Source: own elaboration.

After analysing the results presented in Figure 1, we see that the surveyed drivers in Poland indicate the importance of the "brand familiarity" criterion more than drivers in the Czech Republic. The average calculated on the basis of the respondents' answers was 3.2 for Poland and 2.3 for the Czech Republic. In fact, this is the only noticeable difference between the respondents from both countries. The level of importance of all other criteria can be considered to be practically the same. The most important criterion based on which drivers of both countries make the purchase of engine oils is the viscosity classification and the recommendations of car service providers. On the opposite side of the differential the respondents deemed the "radio and TV ads" criterion to be the least important selection factor. Of the five types of recommendations analysed - oil 
seller, car manufacturer, ASO, car service, and family and friends - recommendations obtained from oil sellers turned out to be the least important.

Overall, the data analysis strongly rejects Hypothesis A: "Consumers from Poland and the Czech Republic have noticeably different decision-making processes when faced with engine oil purchase." We may say with confidence that - somewhat surprisingly - consumers from both countries show a similar pattern of criteria importance. As a result, the segmentation of consumers was performed on the merged data set.

\section{Model-Based Clustering Results}

As explained in the methods section, one of the research goals was to fit a mixture model to the data. The input data was binarized ("important or very important" versus the rest). To avoid a local maximum in the EM algorithm, the optimisation was restarted 100 times with random initialization. A number of components $K$ from 1 to 7 has been investigated. The best solution with respect to the log-likelihood for each of the different numbers of components was obtained (Grün \& Leisch, 2007) and the model selection was made using the information criteria (BIC; Fraley \& Raftery, 1998). Noteworthy, among the checked values of parameter $K$, there was a special one $K=1$. If selected by the $B I C$, it would mean that the data favours the hypothesis of one homogenous group. However, for the present dataset, the BIC very strongly indicates a mixture model with 4 components (segments) as the best one. This finding directly leads to the acceptance of Hypothesis B (HB): "Consumers do not constitute a single homogenous group."

Figure 2 graphically represents the results of the model-based consumer segmentation. Each panel depicts one segment. Each header of the panel provides the size of a given segment. Each row represents one of 13 criteria. The red markings are the same in each panel and serve as a benchmark profile, since this is an importance profile constructed under the assumption of no segmentation. Grey bars represent the probability of choosing given criteria as important or very important by a member of a segment.

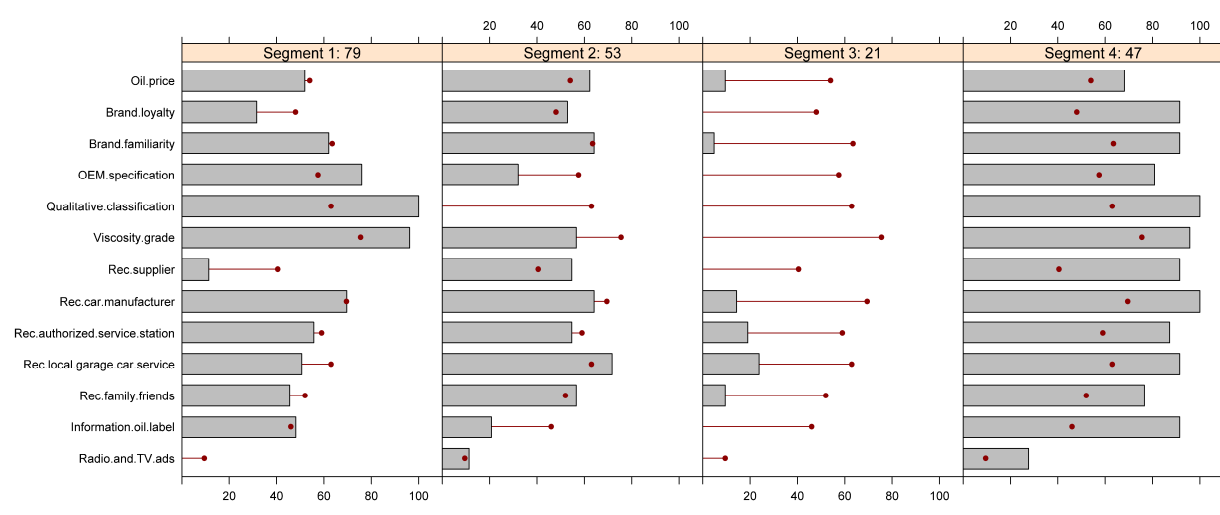

Figure 2. Results of model-based clustering

Source: own elaboration.

Figure 2 shows that segment 1 is the largest one and contains 79 drivers $(39.5 \%$ of the respondents), for whom the most important in the choice of engine oil were: information about the quality classification (100\% probability that members of this segment consider the 
indicated criterion as important or very important), viscosity level (96\%), OEM specification (75\%), and to a lesser extent "brand familiarity" (62\%) and manufacturer's recommendation (69\%). This group includes drivers that can be described as "rational users" who pay attention to technical parameters (viscosity, quality, OEM specifications), follow their knowledge, and - importantly - do not trust the recommendations of sellers (12\%) or radio and television advertisements (0\%). Moreover, they do not show any clear brand attachment (33\%). These findings are not particularly surprising as according to Arndt and May (1981), some consumers view commercial sources of information as problematic due to the unavailability of the perceived motives of the communicator. In a commercial setting, the communicator is perceived as not altogether independent and the recommendations may be deemed biased or exaggerated. Noteworthy, in this group there is approximately the same number of respondents from Poland (35 drivers) as from the Czech Republic (44).

The respondents from segment 2 (53 drivers, $26.5 \%$ of all respondents) pay little attention to the technical aspects of engine oils, such as quality classification (0\%), OEM specifications (31\%), or information on the oil packaging label $(20 \%)$. What counts for them in the first place is the recommendation given by the garage service they return the car to (72\%), assigning the decision-making burden to those who perform the services. As indicated by (Sherif, 1963), less knowledgeable consumers have lower confidence levels in their beliefs than more knowledgeable consumers. Therefore, less knowledgeable consumers are more likely to have a strong reliance on any type of endorsement. Moreover, we should note that respondents in this group have the strongest tendency to rely on the opinions of their family and friends (56\%). The presence of this type of segment for other types of products was also identified by Gil, Andrés, and Salinas (2007), who state that "individuals frequently consider family as a reliable reference in relation to the purchase of certain products." This observation is particularly important for oil producers, since a large number of drivers strongly depend on the recommendations of car mechanics in their choices of engine oil. Therefore, strengthening commercial cooperation with them may translate into increased sales results. However, we should remember that oil price $(61 \%)$ and brand awareness (63\%) are also an important factor for this group of drivers. In other words, such strategy would only make sense if "endorsed" engine oils were not overly expensive or coming from relatively new producers on the market. In the discussed segment there was approximately the same number of respondents from Poland (30 drivers) as well as from the Czech Republic (23).

The third segment is a small group of drivers; about $10 \%$ of all respondents: 12 from Poland and 9 from the Czech Republic. These are respondents for whom all of the assessed criteria are of little or no importance. The presence of such a segment of drivers is not surprising, since similar trends are observed for other types of products. For example, Mourali et al. (2005) claim that - while it is commonly accepted that consumers may engage in pre-purchase information search before making a buying decision - it is suggested that the amount of external search will be limited rather than extensive. In turn, Olshavsky and Granbois (1980) conclude that consumers' behaviour suggests a substantial proportion of purchases does not involve decision-making, not even on the first purchase. Similarly, Hoyer (1984) states that some consumers are not motivated to engage in a great deal of decision-making at the time of purchase, when the product is purchased repeatedly and is relatively unimportant. Thus, we may assume that - for some drivers - the 
purchase of engine oil is of no particular importance. This segment of drivers is potentially prospective for engine oil producers, as it is possible that there are still undiscovered nonstandard features of oils that may convince these people to buy. Moreover, there is no reason to believe that this segment of respondents is a group that approached the survey carelessly or thoughtlessly. These people gave reliable answers to the remaining questions in the survey, which are of no interest to the current study. Therefore, we may assume that such type of drivers represents a small yet present segment.

The fourth segment is similar in number to the second one and includes 47 respondents ( 26 from Poland, 21 from the Czech Republic). This is the most "unusual" segment among the four analysed. Apart from one criterion (radio and television advertising), the respondents considered all of the other criteria to be very important in the purchasing process without explicitly indicating the most significant ones. The literature on consumer choices suggests the existence of such segments, in which consumers' statements of behaviour do not necessarily coincide with their actual behaviour (Rokka \& Uusitalo, 2008; Moisander, 2007).

\section{CONCLUSIONS}

\section{Summary of Findings}

The research results suggest that the importance of all tested criteria (except one) affecting the choice of engine oil brand is practically at the same level for both Polish and Czech drivers. The exception is "brand familiarity." Apparently, Polish drivers indicate the importance of this criterion to a greater extent than drivers from the Czech Republic; however, the difference in numbers is not very striking. We may say that the most important criteria followed by drivers from both countries to purchase engine oils, are the viscosity classification and car manufacturer's recommendations. Radio and TV ads and recommendations of oil sellers turned out to be the least important criteria.

Using model-based clustering, we revealed that consumers do not constitute a single homogenous group. They cluster into four segments with differing importance profiles. We found that the largest consumer segment, over one-third of consumers $(39.5 \%)$, consider the quality classification - viscosity classification and OEM specification - to be the most important criteria in the decision-making process. Furthermore, the attention of any future consumer research into brand attachment should shift from brand loyalty studies towards the study of brand familiarity.

For drivers in the second segment, the recommendations given by car service providers and the opinion of family and friends play the key role in the decision-making process. The third segment consists of a small group of drivers (10\%). These are the respondents for whom all of the assessed criteria are of little or no importance. The last segment is the most "unusual" one because - apart from radio and television advertising - the surveyed drivers consider almost all of the tested criteria as very important in the purchasing process without a clear indication of the most important criteria.

\section{Main Implications for Practice}

The analysis of consumer buying decision-making revealed that there is a need of additional efforts to provide clearly visible technical specifications on the product label. The 
largest extracted segment includes drivers who are mainly guided by these specific data in the purchasing process. In turn, the majority of drivers in segment 2 tend to select their engine oil based on the recommendations of car mechanics. Therefore, closer commercial cooperation with them may translate into increased sales of engine oils. Moreover, all of the respondents are characterised by quite low price-sensitivity.

\section{Research Limitations}

Just as any research, especially empirical, the above analysis has its limitations. These are mainly conditioned by the method of the sample selection and the sample size. The population was limited to engine oil buying men in Poland and the Czech Republic. Female participants of the survey generally gave a negative answer ("no") to the control question "Do you make decisions or participate in the decision-making process when it comes to changing the engine oil?" Another potential limitation of the research, which affects the correctness of its results, are slight deviations in the composition of the studied group from the typical driver population. There is a minor overrepresentation of drivers from cities and drivers with higher education. However, the age structure did not raise any particular concerns. For the above reasons, it is not possible to generalise the results. Thus, further in-depth research on this topic in other countries is still needed.

\section{Suggestions for Future Research}

An interesting direction of future research may be respondents similar to those belonging to the fourth segment presented in the section "Model-based clustering results." Perhaps this type of respondents only seemingly think that all of the decision criteria are very important. These doubts can potentially be resolved with the use of - besides Likert scales survey questions that require respondents to directly identify e.g. three most important oil features. Economics and cognitive psychology traditionally assume that consumer behaviour is rational in the sense that consumers act consistently according to their preferences and beliefs (Rokka \& Uusitalo, 2008). In the case of the consumer segment in question, it is possible that their actions may deviate from their declarations.

\section{REFERENCES}

Aaker, D.A., \& Keller, K.L. (1990). Consumer Evaluations of Brand Extensions. Journal of Marketing, 54(1), 27-41. https://doi.org/10.2307/1252171

Adelaar, T., Chang, S., Lancendorfer, K.M., Lee, B., \& Morimoto, M. (2003). Effects of media formats on emotions and impulse buying intent. Journal of Information Technology, 18(4), 247-266. https://doi.org/10.1080/0268396032000150799

Ahearne, M., Bhattacharya, C.B., \& Gruen, T. (2005). Antecedents and consequences of customercompany identification: Expanding the role of relationship marketing. Journal of Applied Psychology, 90(3), 574-585. https://doi.org/10.1037/0021-9010.90.3.574

Alavijeh, M.R.K., Fattahi, S.S., \& Moshfegh, M. (2019). Comparing the effect of price and the effect of brand on industrial lubricants customer buying choice. SMART Journal of Business Management Studies, 15(2), 58. https://doi.org/10.5958/2321-2012.2019.00015.0

Arndt, J., \& May, F.E. (1981). The Hypothesis of a Dominance Theory of Information Sources. Journal of the Academy of Marketing Science, 9(4), 337-351.

Ayanwale, A.B., Alimi, T., \& Ayanbimipe, M.A. (2005). The Influence of Advertising on Consumer 
Brand Preference. Journal of Social Sciences, 10(1), 9-16. https://doi.org/10.1080/09718923.2005.11892453

Biswas, D., Biswas, A., \& Das, N. (2006). The differential effects of celebrity and expert endorsements on consumer risk perceptions: The role of consumer knowledge, perceived congruency, and product technology orientation. Journal of Advertising, 35(2), 17-31. https://doi.org/10.1080/00913367.2006.10639231

Central Register of vehicles and drivers. Retrieved from www.cepik.gov.pl on August 5, 2018).

Cesky Statisticky Urad. Data for the year 2016-2018. Retrieved from http://czso.cz on August 1, 2019.

Chráska, M., \& Chrásková, M. (2016). Semantic Differential and its Risks in the Measurement of Students' Attitudes. Procedia - Social and Behavioral Sciences, 217, 820-829. https://doi.org/10.1016/j.sbspro.2016.02.155

Cesky Statisticky Urad. Data for the year 2016-2018. Retrieved from http://czso.cz on August 1, 2019.

Davis, L.L. (1987). Consumer Use of Label Information In Ratings of Clothing Quality and Clothing Fashionability. Clothing and Textiles Research Journal, 6(1), 8-14 https://doi.org/10.1177/0887302X8700600102

Dempster, A.P., Laird, N.M., \& Rubin, D.B. (1977). Maximum Likelihood from Incomplete Data Via the EM Algorithm. Journal of the Royal Statistical Society: Series B (Methodological), 39(1), 122. https://doi.org/10.1111/j.2517-6161.1977.tb01600.x

Erdem, T., Swait, J., \& Louviere, J. (2002). The impact of brand credibility on consumer price sensitivity. International Journal of Research in Marketing, 19(1), 1-19. https://doi.org/10.1016/S0167-8116(01)00048-9

Fornell, C. (1992). A National Customer Satisfaction Barometer: The Swedish Experience. Journal of Marketing, 56(1), 6-21. https://doi.org/10.2307/1252129

Foster, B.D., \& Cadogan, J.W. (2000). Relationship selling and customer loyalty: an empirical investigation. Marketing Intelligence \& Planning, 18(4), 185-199. https://doi.org/10.1108/02634500010333316

Fraley, C., \& Raftery, A.E. (1998). How many clusters? Which clustering method? Answers via modelbased cluster analysis. Computer Journal, 41(8), 578-588. https://doi.org/10.1093/comjnl/41.8.578

Gil, R.B., Andrés, E.F., \& Salinas, E.M. (2007). Family as a source of consumer-based brand equity. Journal of Product and Brand Management, 16(3), 188-199. https://doi.org/10.1108/10610420710751564

Grün, B., \& Leisch, F. (2007). FlexMix: An \{R\} Package for Finite Mixture Modelling. R News, 7(1), 813. Retrieved from http://cran.r-project.org/doc/Rnews/ on August 16, 2019.

Hoyer, W.D. (1984). An Examination of Consumer Decision Making for a Common Repeat Purchase Product. Journal of Consumer Research, 11(3), 822. https://doi.org/10.1086/209017

Keller, K. (2008). Strategic Brand Management: building, measuring, and managing brand. 4th edition. Pearson/Prentice Hall. https://doi.org/10.2307/1252315

Kim, M., \& Lennon, S. (2008). The effects of visual and verbal information on attitudes and purchase intentions in internet shopping. Psychology and Marketing, 25(2), 146-178. https://doi.org/10.1002/mar.20204

Krasnowska, G., \& Salejda, A.M. (2011). Ocena wiedzy konsumentów na temat znakowania. Żywność. Nauka. Technologia. Jakość, 1(74), 173-189.

Kuksov, D., Shachar, R., \& Wang, K. (2013). Advertising and consumers' communications. Marketing Science, 32(2), 191-363/ https://doi.org/10.1287/mksc.1120.0753 
Leisch, F. (2004). FlexMix: A General Framework for Finite Mixture Models and Latent Class Regression. Journal of Statistical Software, 11(8). https://doi.org/10.18637/jss.v011.i08

Leisch, F. (2008). FlexMix Version 2: Finite Mixtures with. Journal of Statistical Software, 28(4), 1-35.

McLachlan, G.J., \& Peel, D. (2000). Finite Mixture Models. John Wiley \& Sons, Inc. http://dx.doi.org/10.1002/0471721182

Moisander, J. (2007). Motivational Complexity of Green Consumerism. International Journal of Consumer Studies, 31(4), 404-409. https://doi.org/10.1111/j.1470-6431.2007.00586.x

Morden, T. (1991). Thinking globally and managing locally. European Business Review, 29(2), 70-79. https://doi.org/10.1108/EUM0000000001878

Mourali, M., Laroche, M., \& Pons, F. (2005). Antecedents of consumer relative preference for interpersonal information sources in pre-purchase search. Journal of Consumer Behaviour, 4(5), 307-318. https://doi.org/10.1002/cb.16

Nieżurawski, L., \& Sobków, C. (2015). Role of the information from the food product label in the process of food product purchase. Stowarzyszenie Ekonomistów Rolnictwa i Agrobiznesu, 17(3), 290-296.

Olanipekun, O.J., Rasheed, K.O., \& Sydney, A.A. (2015). Brand Recognition and Impulse Buying Behaviour of. Europan Journal of Business, Economics and Accountancy, 3(5), 51-63.

Oliver, R.L. (2014). Satisfaction: A Behavioral Perspective on the Consumer. A Behavioral Perspective on the Consumer. https://doi.org/10.4324/9781315700892

Olshavsky, R.W., \& Granbois, D.H. (1980). Consumer Decision Making-Fact or Fiction? Comment: Rejoinder. Journal of Consumer Research, 7(3), 333-334. https://doi.org/10.1086/208822

Pawar, P.A., \& Khandelwal, R. (2011). Analysis of Automotive Lubricant Market in India and Marketing Strategies for Rural Markets. Chronicle of The Neville Wadia Institute of Management Studies And Research, 60-64.

POPiHN. (2018). Polish Organisation of Oil Industry and Trade - Annual report. Oil Industry and Trade, 1-52.

Rokka, J., \& Uusitalo, L. (2008). Preference for green packaging in consumer product choices - Do consumers care?. International Journal of Consumer Studies, 32(5), 516-525. https://doi.org/10.1111/j.1470-6431.2008.00710.x

SDA (Car Importers Association). Car fleet overview for the year 2011-2019. Retrieved from http://portal.sda-cia.cz on August 1, 2019.

Sherif, C.W. (1963). Social categorization as a function of latitude of acceptance and series range. Journal of Abnormal and Social Psychology, 67(2), 148-156. https://doi.org/10.1037/h0043022

Smol, M., Avdiushchenko, A., Kulczycka, J., \& Nowaczek, A. (2018). Public awareness of circular economy in southern Poland: Case of the Malopolska region. Journal of Cleaner Production, 197, 1035-1045. https://doi.org/10.1016/j.jclepro.2018.06.100

Sprotles, G.B. \& Kendall, E.L. (1986). A Methodology for Profiling Consumers' Decision-Making Styles. Journal of Consumer Affairs, 20(2), 267-279. https://doi.org/10.1111/j.17456606.1986.tb00382.x

Srivastava, G. (2016). Brand Positioning of Automotive Lubricant in Indian Market. The International Journal of Management, 2(4), 43-55.

Srivastava, G. (2018). Importance of Brand Positioning for Indian Automotive Lubricants Market. Scholars Journal of Economics, Business and Management, 1165-1171. https://doi.org/10.21276/sjebm.2018.5.12.11 
Wedel, M., \& Kamakura, W.A. (2001). Market Segmentation - Conceptual and Methodological Foundations. Boston, MA: Kluwer Academic Publishers. https://doi.org/10.1017/СВ09781107415324.004

Zakir, S. (2011). Consumer Attitude towards Automobile Lubricants: A Case Study of PSO Lubricants. Journal of Independent Studies and Research-Management, Social Sciences and Economics, 9(1), 31-45. https://doi.org/10.31384/jisrmsse/2011.09.1.3

\section{Appendix}

From a purely technical point of view, there are two important aspects that have to be taken into account when it comes to engine oil change. Firstly, one must provide proper engine protection and, secondly, one should address environmental concerns. An optimal oil change time is when it is possible to maintain a balance between the two aspects, i.e. when the oil is changed before it loses its properties but not too early, so as not to have an unnecessary negative impact on the environment. In ideal circumstances, consumers should prioritise these two aspects. However, practice shows that wholly different aspects can be more important to the majority of consumers. The impact of the product attributes (in this study: synthetic oils) on consumer choices may vary depending on their knowledge about the product, but also on their personal preferences. Below, we list, describe, and justify product attributes that were assessed by respondents. The selection of the indicated list of attributes was preceded by literature studies and consultations with industry experts to select a group of attributes that realistically reflect the respondents' decision-making process.

\section{A.1 Price}

According to Foster and Cadogan (2000), price is probably the most important consideration for a typical consumer. Price consciousness is defined as finding the best value, buying at sale prices or the lowest price choice (Sprotles \& Kendall, 1986). Literature analysis provides information that enables the assumption that the price of engine oil should be one of the most important attributes in the respondents' opinion. However, one should be aware that price is often an insufficient criterion for choosing a product - including engine oils - if many goods from the same category are characterised by a similar price level. Moreover, oil change is not a frequent activity, so differences in prices cannot be reinforced by frequent purchases.

\section{A.2 Brand Loyalty and Brand Identification}

It is a common view that prestigious brands and their logotypes attract consumers, thus increasing the probability of first-time and frequent buying of the products that boast a well-known label (Foster \& Cadogan, 2000). Many consumers assign high quality to prestigious brands. Therefore, such brands enjoy greater credibility and, ultimately, greater value (Erdem, Swait, \& Louviere, 2002). Furthermore, brand personality provides links to the brand's emotional and self-expressive benefits for differentiation. This is particularly important for the brands whose products have only slight physical differences, and such include lubricating oils. That is why well-known brands can make products more recognisable for potential consumers (Keller, 2008). However, alongside well-known and global brands, there are many less-known brands on the oil market. 
Brand identification is a fundamental antecedent of brand loyalty and, thus, plays a crucial role in the consumer's brand choice and buying behaviour (Ahearne, Bhattacharya, \& Gruen, 2005). Brand loyalty is defined as "a deeply held commitment to rebuy a preferred product consistently in the future, thereby causing repetitive same-brand purchasing despite situational influences" (Oliver, 2014). Aaker and Keller (1990) believe that loyalty is closely related to many factors; one of the most important ones being the former experience of use. Customers can also be loyal to the brand due to psychological or economic barriers that make changing the product brand difficult. On the other hand, customers can be loyal to a brand, because they are satisfied with the quality and, as a result, they want to keep buying the products of this particular brand (Fornell, 1992).

\section{A.3 Engine Oil Classifications and Specifications}

From a technical point of view, oil classifications and specifications provided by manufacturers are the most reliable criterion for their selection. However, they require considerable knowledge and interest on the part of consumers to correctly navigate in the large number of symbols and pictograms used by producers. The commonly used viscosity classification of engine oils is SAE J300. The Society of Automotive Engineers (SAE) developed a viscosity classification, which is a set of requirements, which divides oils into 11 classes in terms of their viscosity at various temperatures. In addition to viscosity, qualitative classifications are equally important. In Europe, the oil quality testing system of the European Automobile Manufacturers' Association (ACEA) is widely applicable. However, in practice, it is the car manufacturer that determines what parameters the oil must meet in order to be applied to a given engine model. Producers can formulate the requirements in two ways: by providing their own specific standards (e.g. VW505.00) or by using the general ACEA system (e.g. ACEA A4/B3). The qualitative classification elaborated by the American Petroleum Institute (API) in cooperation with the Society of Automotive Engineers (SAE) and the American Society for Testing and Materials (ASTM) is also used around the world. It divides engine oils into two groups, marked as S (Service, for spark ignited engines) and $\mathrm{C}$ (Commercial, for compression ignited engines).

\section{A.4 Information Presented on the Oil Label}

One of the most readily available sources of information about a product is its label. The label serves as a carrier of information about the product, the manufacturer and the product's purpose. Part of the information contained on the label may be represented by symbols, i.e. pictograms. The effectiveness of labels as a source of information is based on the assumption that consumers will want to obtain some information before buying the good and they will use it when making their purchasing decision (Davis, 1987). Depending on the type of product, the amount of information presented on the products will vary, and in many cases these issues are legally regulated, as is the case with foodstuffs. Although consumers often claim that information on labels is an important element of their purchasing decisions, research into the use of such information by consumers when they make actual buying decisions does not provide conclusive evidence. The research conducted among Polish consumers regarding food products shows that over $40 \%$ of consumers rely on the information given on labels (Nieżurawski \& Sobków, 2015). However, a much smaller proportion of respondents (20\%) declare the full understanding of the information placed on product labels (Krasnowska \& Salejda, 2011). In turn, the research 
conducted by Kim and Lennon (2008) shows that consumers may require more detailed information about a product when shopping online in comparison to traditional shopping, because they are then inclined to a more meticulous analysis of the product label.

The amount of information presented on engine oil labels varies greatly. Most often, it is simply indicates the fact of meeting particular standards and specifications. However, as in the case of oil classifications or specifications, such information is understandable only by those who have sufficient knowledge in the field of engine oils. Similarly to the previously described role of the brand in the decision-making process, the quantity and form of presentation of information on the product label can play an important role. Consumers driven by the desire to minimise their mental effort may be willing to transfer responsibility for decision-making to external entities, which in the respondents' opinion may have greater knowledge and competences. This role can be played by industry laboratories or certifying institutions, which can be indicated on the product label.

\section{A.5 Recommendations}

Consumers, who need to make a purchasing decision and simultaneously feel the lack of sufficient knowledge, may want to use the recommendations of other people, who in their opinion are experts in a given field or at least seem to have more knowledge than they do. In particular, these may be recommendations of family members or friends, employees of authorised vehicle service centres, vehicle manufacturers, industry experts or engine oil sellers. This is confirmed by studies (Zakir, 2011), which observe that about $70 \%$ of respondents show a positive attitude towards the opinions of family members regarding engine oil selection. A visible impact of family recommendations was also noticed by Gil et al. (2007). The authors state that family has been considered as a powerful influencer in consumer behaviour and repetitive consumption of a brand in the family may generate a habit in the individual that may explain a subsequent loyalty to that brand. Besides family, servicing car mechanics are often entrusted with the choice of engine oil.

\section{A.6 Radio and Television Advertising}

Morden (1991) is of the opinion that advertising is used to establish the basic awareness of a product or service for a potential customer and it serves as an opportunity for the customer to gain more knowledge about it. The advertiser's primary mission is to reach potential customers and influence their awareness, attitudes, and shopping behaviour (Adelaar, CHang, Lancendorfer, Lee, \& Morimoto 2003; Ayanwale, Alimi, \& Ayanbimipe, 2005). Among the various possible marketing activities, advertising is known for its long-term impact on the consumer (Kuksov, Shachar, \& Wang, 2013). A particular type of advertisement was the subject of the study conducted by Biswas, Biswas, and Das (2006). They find that the advertising involving experts enhances the believability of an advertisement, primarily due to an increased source of credibility. However, most oil advertisements are not product specific. In fact, they are brand advertisements that focus on the level of technological advancement. As a result, consumers find it difficult to select a specific product based on advertising alone. Nevertheless, we may conclude that such advertising strategies strongly affect the overall brand awareness. Research by Zakir (2011) shows that - despite the fact that car users have a positive attitude towards advertised engine oils (about $70 \%$ of respondents) - advertising itself is not the main reason why they choose a particular engine oil. 


\section{Authors}

Contribution share of authors is as follows: Artur Wolak (40\%), Kamil Fijorek (40\%), Grzegorz Zając (10\%), and Vojtěch Kumbár (10\%).

\section{Artur Wolak}

Doctor of Economics (Cracow University of Economics, Poland). Currently works at the Department of Industrial Commodity Science at the Cracow University of Economics. His current research projects focus on improving the accuracy of assessment of physicochemical changes, which occur during actual engine operation.

Correspondence to: Department of Industrial Commodity Science, Cracow University of Economics, 27 Rakowicka St., 31-510 Cracow, Poland, e-mail: artur.wolak@uek.krakow.pl

ORCID 1 http://orcid.org/https://orcid.org/0000-0003-4145-8862

\section{Kamil Fijorek}

Doctor of Economics (Cracow University of Economics, Poland). Currently works at the Department of Statistics at the Cracow University of Economics. His research interests include bankruptcy prediction, energy economics, and panel data analysis.

Correspondence to: Department of Statistics, Cracow University of Economics, 27 Rakowicka St., 31-510 Cracow, Poland, e-mail: kamil.fijorek@uek.krakow.pl

ORCID (ㄱ) http://orcid.org/0000-0003-1262-6425

\section{Grzegorz Zając}

Doctor of Agriculture and Agricultural Engineering (University of Life Sciences in Lublin, Poland). Currently works at the Department of Power Engineering and Transportation at the University of Life Sciences in Lublin. He is currently conducting research on the assessment of physicochemical changes engine oil, which occur during actual engine operation.

Correspondence to: Department of Power Engineering and Transportation, University of Life Sciences in Lublin, Głęboka 28 St., 20-612 Lublin, Poland, e-mail: grzegorz.zajac@up.lublin.pl ORCID (i) http://orcid.org/0000-0002-9025-4551

\section{Vojtěch Kumbár}

Doctor of Technology and Agriculture Machinery (Mendel University in Brno, Czech Republic). Currently works as associate professor at the Department of Technology and Automobile Transport at the Mendel University in Brno. His research is focused on rheology and tribology. Correspondence to: Department of Technology and Automobile Transport, Mendel University in Brno, 1 Zemedelska St., 61300 Brno, Czech Republic, e-mail: vojtech.kumbar@mendelu.cz ORCID (i) http://orcid.org/0000-0003-3987-4613

\section{Acknowledgements and Financial Disclosure}

The publication was funded by appropriations of the Faculty of Commodity Science, Cracow University of Economics, and Faculty of Production Engineering University of Life Sciences in Lublin within the framework of grants to maintain the research potential. 


\section{Copyright and License}

This article is published under the terms of the Creative Commons Attribution - NoDerivs (CC BY-ND 4.0) License http://creativecommons.org/licenses/by-nd/4.0/

Published by the Centre for Strategic and International Entrepreneurship - Krakow, Poland 